5. The use of raw skim milk instead of water resulted in a decrease of the quantity of food eaten; the total calorie intake was only slightly increased.

6. Urine production decreased and water uptake increased when hydrogenated peanut oil or no fat was given in place of lard.

7. The use of raw skim milk to drink in place of water increased urine production and fluid uptake on diets with lard as well as on diets with hydrogenated peanut oil.

\title{
REFERENCES
}

Brown, W. R. \& Burr, G. O. (1936). F. biol. Chem. Ir4, xvi.

Burr, G. O. (1940). In Chemistry and Medicine, p. ro2. [M. B. Visscher, editor.] Minnesota: University Press.

Burr, G. O. (1942). Fed. Proc. I, 224.

Burr, G. O. \& Barnes, R. H. (1943). Physiol. Rev. 23, 256.

Burr, G. O. \& Burr, M. M. (1929). J. biol. Chem. 82, 345.

Burr, G. O. \& Burr, M. M. (1930). F. biol. Chem. 86, 587.

Daubert, B. F. (1949). F. Amer. Oil Chem. Soc. 26, 466.

Deuel, H. J. Jr. (1950). F. Amer. diet. Ass. 26, 255.

Deuel, H. J. Jr. \& Greenberg, S. M. (1950). Fortschr. Chem. org. Naturst. 6, I.

Evans, H. M. \& Burr, G. O. (1926-7). Proc. Soc. exp. Biol., N.Y., 24, 740.

Evans, H. M. \& Lepkovsky, S. (1932). Ұ. biol. Chem. 96, I43.

Stangl, E. (195I). Int. Z. Vitaminforsch. 23, I64.

\section{The Role of Fat in the Diet of Rats}

\section{Influence of Dietary Fats on Growth}

\author{
BY E. AAES-JØRGENSEN AND H. DAM \\ Department of Biochemistry and Nutrition, Polytechnic Institute, Copenhagen
}

(Received 27 February 1954)

The need for a certain amount of fat for optimal growth, development and reproduction of rats is well known (Deuel \& Greenberg, 1950). According to Deuel, Meserve, Straub, Hendrick \& Scheer (1947) diets containing $20-40 \%$ cottonseed oil or margarine gave optimal growth. These authors stated that the effect was in part, but not entirely, attributable to a greater calorie intake on diets containing fat. However, comparison of the nutritive values of different fats can be misleading when based on one dietary level only. Barki, Collins, Elvehjem \& Hart (1950) found optimal effect of various dietary fats, such as butterfat, maize oil, soya-bean oil and coconut oil, at different levels. Similar results were found by von Beznák, von Beznák \& Hajdu (1943), who concluded that the differences in nutritive value of different fats (butterfat, horse fat, soya-bean oil, lard, oleomargarine, linseed oil and rapeseed oil) are dependent not only on the essential fatty acids and fatty acids with six to fourteen $\mathrm{C}$ atoms, but also even more on the ratios of different fatty acids present.

In continuation of previous investigations (Aaes-Jørgensen \& Dam, I954) with lard and hydrogenated peanut oil the experiments recorded here were designed to study further the influence on growth of qualitative and quantitative changes in the dietary fat components. 


\section{EXPERIMENTAL}

Newly weaned female rats were distributed in seventeen groups of six animals. The diet and drinking fluid were given ad lib. during 16 weeks of the experiment. A transparent aqueous suspension of vitamins $A$ and D (Decamin aquosum, Ferrosan Ltd, Copenhagen) was given three times weekly, supplying 1410 i.u. vitamin A and 198 i.u. vitamin $\mathrm{D}_{2}$ /animal/week. The animals were weighed weekly and were killed with chloroform at the end of the experiment.

The composition of the diets is shown in Table $\mathbf{I}$.

Table I. Drinking fluids and percentage composition of diets of the rats

\begin{tabular}{|c|c|c|c|c|c|c|c|c|c|c|c|c|c|c|c|c|c|}
\hline Group no. ... & 10 & II & 12 & I3 & 14 & I5 & I6 & 17 & 18 & I9 & 20 & $2 I$ & 22 & 23 & 24 & 25 & 26 \\
\hline Sucrose & 67 & 67 & 67 & 67 & 67 & 67 & 60 & 60 & 46 & 46 & 57 & 57 & 84 & 74 & 64 & 67 & 67 \\
\hline Extracted casein* & 20 & 20 & 20 & 20 & 20 & 20 & 20 & 20 & 20 & 20 & 30 & 30 & 10 & 20 & 30 & 20 & 20 \\
\hline Salt mixturet & 5 & 5 & 5 & 5 & 5 & 5 & 5 & 5 & 5 & 5 & 5 & 5 & 5 & 5 & 5 & 5 & 5 \\
\hline Vitamin mixturef & 0.5 & 0.5 & 0.5 & 0.5 & 0.5 & 0.5 & 0.5 & 0.5 & 0.5 & 0.5 & 0.5 & 0.5 & 0.5 & 0.5 & 0.5 & 0.5 & 0.5 \\
\hline Choline chloride & 0.5 & 0.5 & 0.5 & 0.5 & 0.5 & 0.5 & 0.5 & 0.5 & 0.5 & 0.5 & 0.5 & 0.5 & 0.5 & 0.5 & 0.5 & 0.5 & 0.5 \\
\hline Lard & 7 & 7 & 0 & 0 & 0 & 0 & 14 & 0 & 28 & 0 & 7 & 0 & 0 & $\circ$ & 0 & $\circ$ & $\circ$ \\
\hline Peanut oil & 0 & 0 & 0 & 0 & 7 & 7 & 0 & o & 0 & 0 & 0 & 0 & $\circ$ & 0 & o & 0 & 0 \\
\hline $\begin{array}{l}\text { Hydrogenated peanut } \\
\left.\text { oil (m.p. } 35-37^{\circ}\right) \S\end{array}$ & 0 & o & 7 & 7 & o & 0 & $\circ$ & 14 & $\circ$ & 28 & $\circ$ & 7 & $\circ$ & $\circ$ & o & 0 & 0 \\
\hline $\begin{array}{l}\text { Hydrogenated whale oil } \\
\left.\text { (m.p. } 35^{-}-37^{\circ}\right) \S\end{array}$ & $\circ$ & o & o & 0 & 0 & $\circ$ & $\circ$ & $\circ$ & 0 & 0 & $\circ$ & 0 & 0 & $\circ$ & 0 & 7 & o \\
\hline Coconut oil & ○ & o & $\circ$ & $\circ$ & $\circ$ & 0 & 0 & 0 & 0 & $\circ$ & o & 0 & 0 & 0 & 0 & 0 & 7 \\
\hline Drinking fluid & W & $\mathbf{R}$ & W & $\mathbf{R}$ & W & $\mathbf{R}$ & W & W & W & W & W & W & W & W & W & W & W \\
\hline
\end{tabular}

$\mathrm{W}=$ water, $\mathrm{R}=$ raw skim milk.

* 'Vitamin test casein', Genatosan, Loughborough, England.

$+\mathrm{McCollum}$ 's salt mixture no. $\mathrm{x} 85$, supplemented with $13.5 \mathrm{mg} \mathrm{KI}, 139 \mathrm{mg} \mathrm{CuSO}_{4} \cdot{ }_{5} \mathrm{H}_{2} \mathrm{O}$ and $556 \mathrm{mg} \mathrm{MnSO}_{4} \cdot 4 \mathrm{H}_{2} \mathrm{O}$ per $100 \mathrm{~g}$.

$\ddagger 0.5 \mathrm{~g}$ of the mixture consisted of: biotin $0.05 \mathrm{mg}$, folic acid $0.05 \mathrm{mg}, p$-aminobenzoic acid $35 \mathrm{mg}$, thiamine hydrochloride $5 \mathrm{mg}$, riboflavin $5 \mathrm{mg}$, pyridoxin hydrochloride $5 \mathrm{mg}$, calcium pantothenate $5 \mathrm{mg}$, nicotinic acid $8 \mathrm{mg}$, inositol I $5 \mathrm{mg}$, ascorbic acid $5 \mathrm{mg}$, DL- $\alpha$-tocopherol acetate (Ephynal, Roche) $5 \mathrm{mg}$, dicalcium salt of 2-methyl-1:4-naphthohydroquinone diphosphoric acid (Synkavit, Roche Products Ltd.) $1 \mathrm{mg}$, and sucrose to $500 \mathrm{mg}$.

$\S$ Dansk Soyakagefabrik Ltd., Copenhagen.

\section{RESULTS}

A summary of the average weights in the different groups at the end of the 16 -week experimental period is presented in Table 2. Comparison between groups Io, I2 and 14 on diets containing $7 \%$ fat with water showed that the growth rate of the animals in group $\mathrm{I}_{4}$ (peanut oil) was equal to that in group Io (lard). The animals in these two groups grew much better than the rats on the $7 \%$ hydrogenated peanut-oil diet (group 12).

In the corresponding groups ( I I, I3 and I5) with raw skim milk instead of water, group I 5 (peanut oil) grew much faster than group I I (lard) and very much faster than group I3 (hydrogenated peanut oil). When raw skim milk (group I3) was supplied instead of water (group 12) with the hydrogenated peanut-oil diet a growthstimulating effect was seen. The same result was found with peanut oil as dietary fat (groups $\mathrm{I}_{4}$ and $\mathrm{I}_{5}$ ).

The growth-stimulating effect obtained by substituting raw skim milk for water in the hydrogenated peanut-oil ration was not sufficient to increase the growth rate of 
this group (group $\mathrm{r}_{3}$ ) to the level found for animals on the lard diet with water (group Io).

The animals on diets with $7 \%$ fat and water as drinking fluid apparently grew at much the same rate whether lard, peanut oil or coconut oil was used as dietary fat component (groups Io, 14 and 26 ). In groups 12 and 25 , on hydrogenated peanut oil and hydrogenated whale oil respectively, the growth rates were considerably slower than those of groups 10,14 and 26. Further, the growth curves of groups 12 and 25 were almost identical throughout the experiment.

\section{Table 2. Mean weights of rats at the beginning and at the end of $\mathrm{I} 6$ weeks}

\begin{tabular}{|c|c|c|c|}
\hline Group no. & Diet characteristics & $\begin{array}{c}\text { Initial } \\
(\mathrm{g})\end{array}$ & $\begin{array}{l}\text { Final, with its } \\
\text { standard error } \\
\text { (g) }\end{array}$ \\
\hline 10 & $7 \%$ lard, water & $43 \cdot 3$ & $197.2 \pm 10.9$ \\
\hline II & $7 \%$ lard, raw skim milk & $43 \cdot 3$ & $197 \cdot 2 \pm 6 \cdot 0$ \\
\hline 12 & $7 \%$ hydrogenated peanut oil, water & $43^{\circ} \circ$ & $165 \cdot 8 \pm 7 \cdot 7$ \\
\hline $\mathbf{I} 3$ & $7 \%$ hydrogenated peanut oil, raw skim milk & $42 \cdot 8$ & $175 \cdot 9 \pm 4 \cdot 3$ \\
\hline 14 & $7 \%$ peanut oil, water & $43 \cdot 2$ & $200 \cdot 7 \pm 10 \cdot 1$ \\
\hline I5 & $7 \%$ peanut oil, raw skim milk & $43 \cdot 0$ & $246 \cdot 0 \pm 12 \cdot 6$ \\
\hline 16 & $14 \%$ lard, water & $43 \cdot 2$ & $195.4 \pm 6.3$ \\
\hline I7 & $14 \%$ hydrogenated peanut oil, water & 43.0 & $155.5 \pm 7 \cdot 4$ \\
\hline 18 & $28 \%$ lard, water & $43 \cdot 0$ & $203.2 \pm 3.4$ \\
\hline I9 & $28 \%$ hydrogenated peanut oil, water & $42 \cdot 8$ & $140 \cdot 0 \pm 7 \cdot 8$ \\
\hline 20 & $7 \%$ lard, $30 \%$ casein, water & $43 \cdot 0$ & $194.9 \pm 9.4$ \\
\hline $2 \mathbf{r}$ & $7 \%$ hydrogenated peanut oil, $30 \%$ casein, water & $43 \cdot 2$ & $176 \cdot 2 \pm 8 \cdot 7$ \\
\hline 22 & Fat-free, ro $\%$ casein, water & $43 \cdot 2$ & $98 \cdot 7 \pm 13 \cdot 2$ \\
\hline 23 & Fat-free, $20 \%$ casein, water & 44.6 & $149.8 \pm 13.7$ \\
\hline 24 & Fat-free, $30 \%$ casein, water & $43 \cdot 0$ & $156.2 \pm 10.2$ \\
\hline 25 & $7 \%$ hydrogenated whale oil, water & $45^{\circ} \circ$ & $162 \cdot 7 \pm 8 \cdot 1$ \\
\hline 26 & $7 \%$ coconut oil, water & $44 \cdot 5$ & $197 \cdot 6 \pm 5 \cdot 3$ \\
\hline
\end{tabular}

Increasing the amounts of lard in the diets (from 7 to $28 \%$ ) resulted in only very small differences in the growth rate (groups 10, 16 and 18). Diets with increasing amounts $(7-28 \%$ ) of hydrogenated peanut oil (groups 12, I 7 and 19) produced a decrease in growth rate. The growth rate of the animals receiving $28 \%$ hydrogenated peanut oil (group r9) was to a remarkable degree less than that of the animals receiving $7 \%$ of it. We have no explanation of a temporary fall in growth rate of the animals on the diet containing $14 \%$ hydrogenated peanut oil (group 17 ) occurring between the $5^{\text {th }}$ and 6 th experimental week. Finally, the growth rates of the animals receiving I 4 or $28 \%$ hydrogenated peanut-oil diets (groups I 7 and I9) were significantly less than those of the animals on the lard diets (groups 10, 16 and 18 ).

Increasing the amount of alcohol-extracted casein in the fat-free diets (groups 22-24), even from 20 to $30 \%$, improved the growth curve. The individual growth rates of the animals in these groups varied considerably as seen from the relatively high value of the standard error of the mean (Table 2). Diets with $7 \%$ lard (group 10) and $7 \%$ peanut oil (group 14 ), respectively, resulted in growth curves considerably higher than those of the groups on the fat-free rations (groups 22-24). The growth curve of the animals on the $7 \%$ hydrogenated peanut-oil diet with $20 \%$ casein (group I2) was almost equal to that of the animals on a fat-free diet with $30 \%$ casein (group 24) and 
somewhat higher than for those on the fat-free diet with $20 \%$ casein (group 23). Only the animals in the group with $10 \%$ casein and no fat (group 22) grew significantly more slowly than those on the diet containing $7 \%$ hydrogenated peanut oil with $20 \%$ casein (group 12).

With extracted casein up to $30 \%$ in the fat-free diets (groups 23 and 24 ), growth rate was markedly stimulated, exceeding that with diets containing $28 \%$ hydrogenated peanut oil and $20 \%$ casein (group 19).

An increase in the content of extracted casein from 20 to $30 \%$ in diets with $7 \%$ lard (groups 10 and 20 ) did not influence growth rate. No effect of changing the drinking fluid from water to raw skim milk was found on a diet with $7 \%$ lard (groups Io and I I).

The animals on $7 \%$ hydrogenated peanut oil showed an increase in growth rate when the drinking fluid was changed from water to raw skim milk (groups 12 and 13 ) as well as when the dietary content of extracted casein was increased from 20 to $30 \%$ (groups 12 and 21 ). The animals receiving $7 \%$ hydrogenated peanut oil and $30 \%$ extracted casein and water (group $2 \mathrm{I}$ ) grew at the same rate as those receiving $7 \%$ hydrogenated peanut oil and $20 \%$ extracted casein and raw skim milk (group 13). Neither group 21 nor group I3 grew nearly as well as the animals on $7 \%$ lard and $20 \%$ extracted casein and water (group ro).

Descriptions of the macroscopical and histological appearance of the kidneys and of the influence of the various diets on food and fluid intake and on urine production are being prepared for publication elsewhere.

\section{DISCUSSION}

Although coconut oil has a rather low linoleic-acid content, namely $\mathrm{I} \cdot 6-2 \cdot 6 \%$ (Bailey, I945), it is interesting to note that the growth rate of animals on a $7 \%$ coconut-oil dietary level (group 26) was equal to that of animals on the $7 \%$ lard or $7 \%$ peanut-oil diet (groups to and I4). Barki et al. (1950) found that changing the level of coconut oil in the diet did not result in significant changes in growth, although in general the gains on coconut oil were low. At the time when these experiments were carried out it was supposed that female rats needed 10-20 $\mathrm{mg}$ linoleic acid daily for normal growth (Greenberg, Calbert, Savage \& Deuel, 1950). If each animal consumes Io $\mathrm{g}$ of the diet with $7 \%$ coconut oil daily it will get I I-18 mg linoleic acid/day.

Feeding either hydrogenated peanut oil or hydrogenated whale oil on the $7 \%$ dietary level resulted in a decrease of the growth rate to the same extent. The two oils are hydrogenated selectively, and to the same melting point $\left(35-37^{\circ}\right)$.

Peanut oil contains about $27 \%$ linoleic acid (Deuel \& Greenberg, 1950) and whale oil a much smaller amount, $c$. I I-12\% (Schweiger, I938). If there still were some linoleic acid left in the peanut oil after the relatively low degree of hydrogenation, an increase of the dietary fat level should have increased the amount of linaleic acid received daily by rats on this diet. From the weight gains it is seen that growth decreased. This finding seems to be in accordance with the idea that increasing dietary fat levels increases the demand for essential fatty acids (Deuel, Greenberg, Anisfeld \& Melnick, I95 I). However, a possible toxic effect of a compound or compounds in the hydrogenated oil cannot be excluded. 
The increased growth rate of the animals on diets containing hydrogenated peanut oil obtained by supplementation with casein or by changing the drinking fluid from water to raw skim milk was in accordance with earlier results from this laboratory (Aaes-Jørgensen \& Dam, 1954).

SUMMARY

I. Female rats reared on diets containing either $7 \%$ lard, $7 \%$ peanut oil or $7 \%$ coconut oil showed essentially the same growth rate throughout 16 weeks of experiment.

2. Hydrogenated peanut oil or hydrogenated whale oil fed at a $7 \%$ level gave the same average growth rate, which was to a remarkable degree less than the average growth rates of the groups fed $7 \%$ lard, $7 \%$ peanut oil or $7 \%$ coconut oil.

3. Increase in the amount of lard from 7 to $I 4$ and $28 \%$ of the diet showed only little influence on the average growth rate.

4. Increase in the dietary levels of hydrogenated peanut oil from 7 to 14 and $28 \%$ decreased the average growth rate considerably.

5. Increase in the protein level in the fat-free diets from 20 to $30 \%$ increased the growth rate somewhat.

6. The growth rate of rats reared on a diet with $28 \%$ hydrogenated peanut oil and $20 \%$ casein was inferior to that of the animals on a fat-free diet containing $20 \%$ casein.

7. Increase in the level of extracted casein from 20 to $30 \%$ in the diets with $7 \%$ hydrogenated peanut oil or change of the drinking fluid from water to raw skim milk improved the growth rate, but not up to the level of growth of animals on a $7 \%$ lard diet with water.

\section{REFERENCES}

Aaes-Jørgensen, E. \& Dam, H. (1954). Brit. F. Nutr. 8, 281.

Bailey, A. E. (1945). Industrial Oil and Fat Products. New York: Interscience Publishers, Inc.

Barki, V. H., Collins, R. A., Elvehjem, C. A. \& Hart, E. B. (1950). F. Nutr. 40, 383 .

Deuel, H. J. Jr. \& Greenberg, S. M. (1950). Fortschr. Chem. org. Naturst. 6, 1.

Deuel, H. J. Jr., Greenberg, S. M., Anisfeld, L. \& Melnick, D. (195 I). F. Nutr. 45, 535.

Deuel, H. J. Jr., Meserve, E. R., Straub, E., Hendrick, C. \& Scheer, B. T. (1947). F. Nutr. 33, 569.

Greenberg, S. M., Calbert, C. E., Savage, E. E. \& Deuel, H. J. Jr. (1950). F. Nutr. 4I, 473.

Schweiger, A. (1938). Fette u. Seif. 45, 64.

von Beznák, A. V., von Beznák, M. V. \& Hajdu, I. (1943). Ernährung, 8, 209. 